IdeAs

Idées d'Amériques

$7 \mid 2016$

Cinéma et histoire dans les Amériques

\title{
Le 4 juillet 1776 : Alors et à travers les siècles
}

\section{Bertrand Van Ruymbeke}

\section{OpenEdition}

\section{Journals}

Electronic version

URL: https://journals.openedition.org/ideas/1624

DOI: 10.4000/ideas.1624

ISSN: 1950-5701

\section{Publisher}

Institut des Amériques

Electronic reference

Bertrand Van Ruymbeke, "Le 4 juillet 1776 : Alors et à travers les siècles", IdeAs [Online], 7| 2016

Online since 19 July 2016, connection on 19 October 2022. URL: http://journals.openedition.org/ideas/ 1624 ; DOI: https://doi.org/10.4000/ideas. 1624

This text was automatically generated on 19 October 2022

\section{(c) (i) (9)}

Creative Commons - Attribution-NonCommercial-NoDerivatives 4.0 International - CC BY-NC-ND 4.0 https://creativecommons.org/licenses/by-nc-nd/4.0/ 


\title{
Le 4 juillet 1776 : Alors et à travers les siècles
}

\author{
Bertrand Van Ruymbeke
}

1 Le 4 juillet 1776, le Congrès Continental, qui se réunit à Philadelphie, en Pennsylvanie, depuis 1774, adopte la Déclaration d'Indépendance. Treize colonies britanniques d'Amérique du Nord, du New Hampshire à la Géorgie, deviennent des «États libres et indépendants ». Mémorable, l'année 1776 se révèle une année pivot. Reprenons les faits.

2 En 1763, à l'issue de la guerre de Sept Ans, la Grande-Bretagne bat les Français et conquiert la Nouvelle-France. Lors des négociations du traité de Paris, elle reçoit aussi la Floride des Espagnols. Désormais seuls maîtres à l'est du Mississippi, les Britanniques réorganisent leur empire nord-américain. Ils créent la province du Québec, dont la limite méridionale pénètre dans le Pays de l'Ohio, au sud des Grands Lacs, et deux provinces en Floride (La Floride Orientale et la Floride Occidentale). Victorieuse mais terriblement endettée, la Grande-Bretagne, qui a besoin de nouvelles ressources financières, met en place, pour la première fois, une taxe fiscale sur les colonies, avec le vote du Stamp Act (1765). Les colons américains ne l'acceptent pas. S'ensuivent une guerre pamphlétaire, des violences à l'encontre des agents de Sa Majesté dans les principales villes portuaires et un boycott des produits britanniques. Première victoire pour les Américains: en 1766 le Parlement abroge le Stamp Act mais vote aussi le Declaratory Act, s'autorisant désormais à légiférer pour les colonies « dans n'importe quel domaine que ce soit ».

3 Après une période de relative accalmie, intervient la Boston Tea Party en décembre 1773. Londres a décidé de sauver de la banqueroute la East India Company, qui finance et organise alors la colonisation de l'Inde, en lui attribuant l'exclusivité du marché nordaméricain pour son thé. Un groupe de Bostoniens grimés en Amérindiens jette pardessus bord la cargaison de thé des navires de la Compagnie ancrés dans la rade. La réaction britannique est brutale: le port de Boston est fermé et la ville occupée militairement. L'intention de Londres est de couper le Massachusetts des autres colonies avec ces mesures ciblées, appelées Lois Coercitives à Londres et Lois 
Intolérables de l'autre côté de l'Atlantique. Cette stratégie ne fonctionne pas. Les colonies restent solidaires. En avril 1775, la guerre éclate et en juin le Congrès nomme le Virginien George Washington commandant en chef des forces américaines.

4 Les six premiers mois de l'année 1776 s'avèrent décisifs. En janvier, le Britannique Thomas Paine, à Philadelphie depuis 1774, publie son Common Sense. Un brûlot antimonarchique qui rend l'indépendance des colonies non seulement souhaitable mais possible. Progressivement, le sens du mot indépendance ou independency, change de sens. Alors qu'il signifiait jusqu'alors non pas une indépendance vis-à-vis du Parlement mais une dépendance vis-à-vis de la Couronne, il prend son sens d'indépendance vis-àvis de la métropole. En juin 1776, le Virginien Richard Henry Lee soumet au Congrès une résolution proposant aux Treize Colonies de devenir «des États libres et indépendants ». Une Déclaration d'Indépendance est de suite rédigée, principalement par l'éloquent planteur virginien Thomas Jefferson. Le 4 juillet, le Congrès adopte cette Déclaration dans une version débattue et remaniée. Les Treize Colonies deviennent les États-Unis d'Amérique. Toute négociation avec Londres est désormais exclue, un point de non-retour a été atteint.

5 Le dossier que nous présentons ici se propose d'étudier tout d'abord l'impact de cet événement auprès des Amérindiens et dans les colonies hispano-américaines. Puis un troisième article analyse comment et dans quels contextes, les Américains ont commémoré ce moment d'indépendance à la fois en 1876, 1976 et 2016.

6 Comme pendant la guerre de Sept Ans (1754-1763), les nations amérindiennes jouèrent un rôle-clé dans le conflit qui oppose les colons américains aux Britanniques. Une grande activité diplomatique doit être déployée par chaque camp afin de gagner telle ou telle nation à sa cause. Les nations amérindiennes sont très nombreuses, d'un poids militaire inégal et ont chacune entretenu des relations différentes avec les colons installés sur leurs terres. D'une manière globale, les Amérindiens ont plutôt soutenu les Britanniques mais la situation varie grandement de groupe à groupe et de région en région. Dans son article, Anne-Marie Libério nous propose un gros plan sur les Delawares, nation algonquine du «Pays de l'Ohio ». L'étude souligne la complexité des rapports entre les nations amérindiennes et la nouvelle république américaine, où se mêlent inextricablement l'héritage et la présence britanniques, la spéculation foncière, l'expansion du peuplement, les campagnes militaires et l'activité missionnaire et diplomatique.

7 Quel impact et quelle influence le 4 juillet 1776 a-t-il connu dans les colonies hispanoaméricaines? Voici une question essentielle pour l'histoire des Amériques à laquelle répond Clément Thibaud dans son essai. Les indépendances dans les colonies espagnoles d'Amérique furent-elles davantage influencées par 1776, 1789 ou 1810-1812 (événements de Cadix)? Au-delà de ce débat historiographique, Clément Thibaud analyse le cas du Venezuela en notant mutatis mutandis une analogie avec les États-Unis dans le processus constitutionnel. On y observe d'ailleurs la même ambiguïté sur le sens du mot indépendance. Quant à la Déclaration d'Indépendance du Venezuela, elle s'inspire sans équivoque de celle de Jefferson. Clément Thibaud souligne aussi l'importance au Venezuela du modèle républicain états-unien, lui-même inspiré par les écrits de Montesquieu.

8 Françoise Coste nous projette plus loin dans le temps en 1876 et en 1976, lorsque les États-Unis fêtent leur Centenaire et leur Bicentenaire respectivement. En 1876, les Américains sont à un tournant de leur histoire: la guerre de Sécession a mis fin à 
l'esclavage et l'après-guerre, appelé Reconstruction, se termine. L'Amérique commence alors sa mue de pays essentiellement agricole en puissance industrielle, économique, et financière, une métamorphose qui s'accomplira sur un demi-siècle jusqu'à la Première Guerre mondiale. Comme le montre Françoise Coste, cette nouvelle Amérique est incarnée par l'Exposition du Centenaire qui se tient à Philadelphie, ville de la Déclaration d'Indépendance et désormais grand centre industriel. Le Centenaire voit une Amérique réconciliée - surtout entre blancs-, optimiste et triomphante, au lendemain de la plus grave crise de leur histoire. Un siècle plus tard, l'Amérique va mal, atteinte et affaiblie par le scandale du Watergate, les séquelles de la désastreuse et très contestée guerre du Vietnam, la contre-culture, les émeutes dans les campus universitaires, et le choc pétrolier. L'Amérique ne semble plus triompher ni rayonner. Un Bicentenaire morose qui voit s'imposer l'individualisme et la grande consommation. Comme le souligne Françoise Coste, à l'inverse du Centenaire, le Bicentenaire se distingue par la parcellisation et la communautarisation du phénomène commémoratif, tout en réussissant néanmoins à préserver intact un message patriotique uniforme.

Devenu fête nationale états-unienne, la 4 juillet 1776, au-delà du contexte angloaméricain spécifique, s'avère un événement non seulement atlantique mais aussi planétaire dans son influence, notamment textuelle, sur la longue durée, comme l'a remarquablement montré l'ouvrage de David Armitage, The Declaration of Independence. A Global History (Cambridge, Mas., 2008). Le présent dossier nous fait réfléchir à certains aspects de cette question.

\section{AUTHOR}

\section{BERTRAND VAN RUYMBEKE}

Bertrand Van Ruymbeke est professeur de civilisation américaine à l'Université de Paris 8 et membre senior de l'Institut Universitaire de France. Il est auteur de l'Amérique avant les États-Unis. Une histoire de l'Amérique anglaise (2013, nouvelle édition poche 2016) et de From New Babylon to Eden. The Huguenots in France and their Migration to Colonial South Carolina (2006). Il a coordonné The Atlantic World of Anthony Benezet (1713-1784). From French Reformation to North American Quaker Antislavery Activism (2016), A Companion to the Huguenots (2016), Réforme et Révolutions (2012), Les huguenots et l'Atlantique (2009-2012), Naissance de l'Amérique du Nord. Les Actes fondateurs (2008), Constructing Early Modern Empires. Proprietary Ventures in the Atlantic World 1500-1700 (2007), Protestantisme et Autorité (2005) et Memory and Identity. The Huguenots in France and the Atlantic Diaspora (2003). 